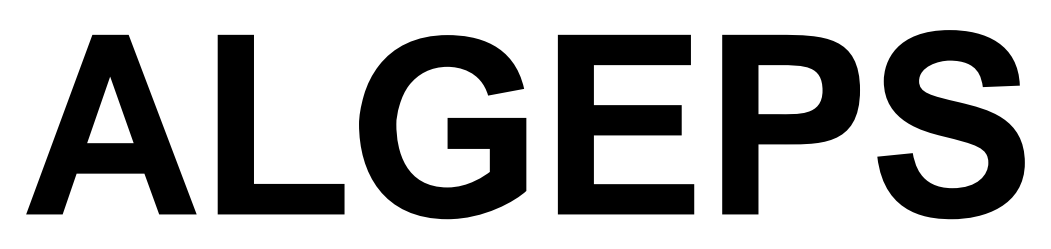

REVISTA DE GEOLOGIA, SÈRIE B no 583 - Març del 2012

ISSN $1132-7014$

D.L.B. 28.178 - 92

12 pàgines

\title{
RECORRIDO DESDE BINÉFAR A SAN ESTEBAN DE LITERA, AZANUY Y A ALINS DEL MONTE, A TRAVÉS DEL PATRIMONIO GEOLÓGICO Y MINERO DE LAS COMARCA DE LA LITERA
}

Josep M. Mata-Perelló 


\section{RECORRIDO DESDE BINÉFAR A SAN ESTEBAN DE LITERA, AZANUY Y A ALINS DEL MONTE, A TRAVÉS DEL PATRIMONIO GEOLÓGICO Y MINERO DE LAS COMARCA DE LA LITERA}

\section{ADVERTENCIAS PREVIAS}

Como en otros recorridos de RECONOCIMIENTO GEOLÓGICO (o de RECONOCIMIENTO GEOLÓGICO Y MINERO), el recorrido se compondrá de diversas PARADAS. En este caso serán seis.

Por otra parte, habrá que tener en cuenta, en todo momento, especialmente antes de empezar los recorridos de los diferentes tramos, el estado de los caminos y carreteras, por donde transitará el recorrido. Al respecto, cabe decir que prácticamente todos estos tramos se halla en buenas condiciones.

Finalmente, como ya hacemos en otros recorridos similares, queremos decir que hace falta tener un cuidado muy especial en el respeto a la naturaleza, a lo largo de todo el recorrido del itinerario, y también fuera de él.

\section{BREVE INTRODUCCIÓN GEOLÓGICA}

El recorrido de este itinerario, se desarrollará exclusivamente por dos de las tres unidades geológicas que constituyen el suelo y el subsuelo de Aragón. Concretamente se iniciará en la Depresión Geológica del Ebro (en la localidad de Binéfar). Luego, tras sobrepasar Azanuy, el recorrido penetrará en otra de las tres unidades geológicas, concretamente en los Pirineos, en donde finalizará el recorrido, cerca de Alins.

Así, a lo largo de todo de todo el recorrido del itinerario, se irán encontrando inicialmente afloramientos cenozoicos, en su mayoría de carácter arcilloso, yesoso y calcolutítico, pertenecientes al Oligoceno.

Luego, ya dentro del recorrido por los Pirineos, se Irán encontrando afloramientos triásicos del Keuper (con niveles arcillosos y yesosos, así como afloramientos de rocas ofíticas). Asimismo, encontraremos también afloramientos de los materiales carbonatados del Cretácico, dentro de los afloramientos pirenaicos de las Sierras Marginales, en el denominado Pirineo Meridional.

Asimismo, a menudo, encontraremos afloramientos de los materiales detríticos cuaternarios, por encima de los anteriores 


\section{BREVE INTRODUCCIÓN GEOGRÁFICA}

El recorrido del presente itinerario se efectuará exclusivamente por una comarca aragonesa, la de la Litera / Llitera, de doble nominación en función de la lengua. Así, se iniciará en la propia capital comarcal, en la ciudad de Binéfar, para dirigirse luego hacía el Norte. El recorrido terminará en la población de Alins del Monte.

En este recorrido, se circulará por los términos municipales de: Binéfar, San Esteban de Litera y Azanuy - Alins, todos ellos de la comarca de la Litera / Llitera, en donde se habrá iniciado el recorrido.

Esta comarca, gravita en torno a dos ríos de la misma cuenca: el Noguera Ribagorzana que drena los sectores orientales y el Cinca que hace lo propio con los sectores occidentales. En cuanto al recorrido del itinerario, circulará íntegramente por estos últimos.

\section{OBJETIVOS GENERALES DE ESTE ITINERARIO}

En este itinerario, los objetivos generales que se han de conseguir, se pueden concretar en los siguientes aspectos:

1.- Estudio y reconocimiento de los materiales cenozoicos (en buena parte del Oligoceno y del Mioceno, según los lugares) situados en la Depresión Geológica del Ebro, que iremos encontrando a lo largo del recorrido del itinerario, entre las inmediaciones de Binéfar, San Esteban de Litera y Azanuy.

2.- Visión de algunas de las antiguas explotaciones encontradas a lo largo del recorrido del itinerario. En concreto de;

2A) de diversas explotaciones de yeso, situadas en los municipios de San Esteban de Litera y Azanuy, entre los afloramientos cenozoicos.

2B) de diversas explotaciones de gravas cuaternarias, situadas en el cauce del río Sosa, entre San Esteban de Litera y Azanuy.

2C) de una antigua explotación de una mineralización de galena, de carácter estratiforme, situada entre los materiales carbonatados del Cretácico.

3.- Observación del impacto producido por las actividades mineras. I si se da el caso, de las restauraciones realizadas para paliar este impacto.

4.- Visión de los diferentes lugares directamente relacionados con el Patrimonio Geológico y Minero que iremos encontrando a lo largo del recorrido del presente itinerario

\section{ANTECEDENTES BIBLIOGRÁFICOS}

En relación con este itinerario, no conocemos ningún antecedente, relativo a otro itinerario que discurra por este lugar. En este sentido, este itinerario ya constituye un antecedente, si no estamos equivocados. Existen antecedentes en itinerarios cercanos 
nuestros: MATA - PERELLÓ (1990, 1991, 1996 t 2002); así como en MATA PERELLÓ y MONTANÉ GARCÍA (2002 y 2004). Aunque se trata de recorridos no coincidentes con el que ahora presentamos.

Por otra parte, haremos mención de algunos trabajos, de carácter geológico generalista, que corresponden a los trabajos del IGME (1972, 1974 y 1975), relativos al Mapa Geológico de España (a Escala 1.200.000), al Mapa Metalogenético de España y al Mapa de Rocas Industriales de España También cabe mencionar a GUIMERÁ et altri (1992), así como a RIBA et altri (1976).

Con respecto a las mineralizaciones que iremos encontrando, mencionaremos los trabajos de: CALVO et altri (1988); MAESTRE (1845); así como nuestros trabajos: MATA-PERELLÓ (1987 y 1998).

También mencionaremos el trabajo de PRAMES (2005) dedicado a la comarca del Campo de Belchite. Así como el del GOBIERNO DE ARAGÓN (2001), dedicado a los Puntos de Interés Geológico de Aragón.

Finalmente, diremos que todos estos trabajos (así como otros que ahora no hemos aludido), figurarán mencionados, por orden alfabético, en el apartado dedicado a las REFERENCIAS BIBLIOGRÁFICAS.

\section{RECORRIDO DEL ITINERARIO}

Este recorrido se iniciará en las inmediaciones de la población de Binéfar (la capital comarcal), en donde se realizará una parada. Luego, el recorrido se dirigirá hacia la población de San Esteban de Litera, en donde se realizaran dos nuevas paradas, siempre dentro de la Depresión Geológica del Ebro. Tras las paradas anteriores, el recorrido se dirigirá hacía la población de Azanuy, realizándose dos nuevas paradas en torno al cauce del río Sosa, a medio camino de los dos pueblos mencionados. Tras ello, el recorrido se dirigirá hacía Azanuy, des de donde se dirigirá a Alins del Monte. Durante este trayecto se efectuará una nueva parada. Finalmente, tras sobrepasar el último pueblo mencionado, finalizará el recorrido en una antigua explotación minera.

\section{DESCRIPCIÓN DEL ITINERARIO}

Como de costumbre, haremos una serio de PARADAS (o ESTACIONES), en donde se realizaran diversas explicaciones en torno a las características del lugar en donde se halla la PARADA. Por otra parte, en ellas haremos mención del término municipal dónde se encuentran, así como del número del "Mapa Topográfico Nacional (a escala 1:50.000, que indicaremos entre paréntesis. Así, ahora (en este recorrido) utilizaremos solamente dos hojas: concretamente la 288 (o de Fonz) y la $\mathbf{3 2 6}$ (o de Monzón). Todas las paradas se ubicaran en alguna de estas dos hojas mencionadas, aunque la mayoría están en la segunda.

Así, la relación ordenada de las paradas que constituyen el recorrido de este itinerario, es la siguiente: 
PARADA 1. ANTIGUA FÁBRICA DE CERÁMICA DE BINÉFAR, (término municipal del Binéfar, comarca de la Litera / Llitera). (Hoja 326).

El recorrido del presente itinerario lo iniciaremos en la localidad de Binéfar (la capital comarcal de la Litera / Llitera). Y concretamente lo iniciaremos frente a la antigua fábrica de cerámica, actualmente cerrada /VER LA FOTOGRAFÍA DE LA PORTADA DEL ITINERARIO).

La población de Binéfar se encuentra situada en plena Depresión Geológica del Ebro. Así, predominan por doquier afloramientos de los materiales cenozoicos del Oligoceno, en tránsito al Mioceno.

En este lugar hubo una antigua fábrica de cerámica. En ella se utilizaban materiales calcolutíticos extraídos en las cercanías. Sin embargo, en la actualidad la fábrica se halla cerrada.

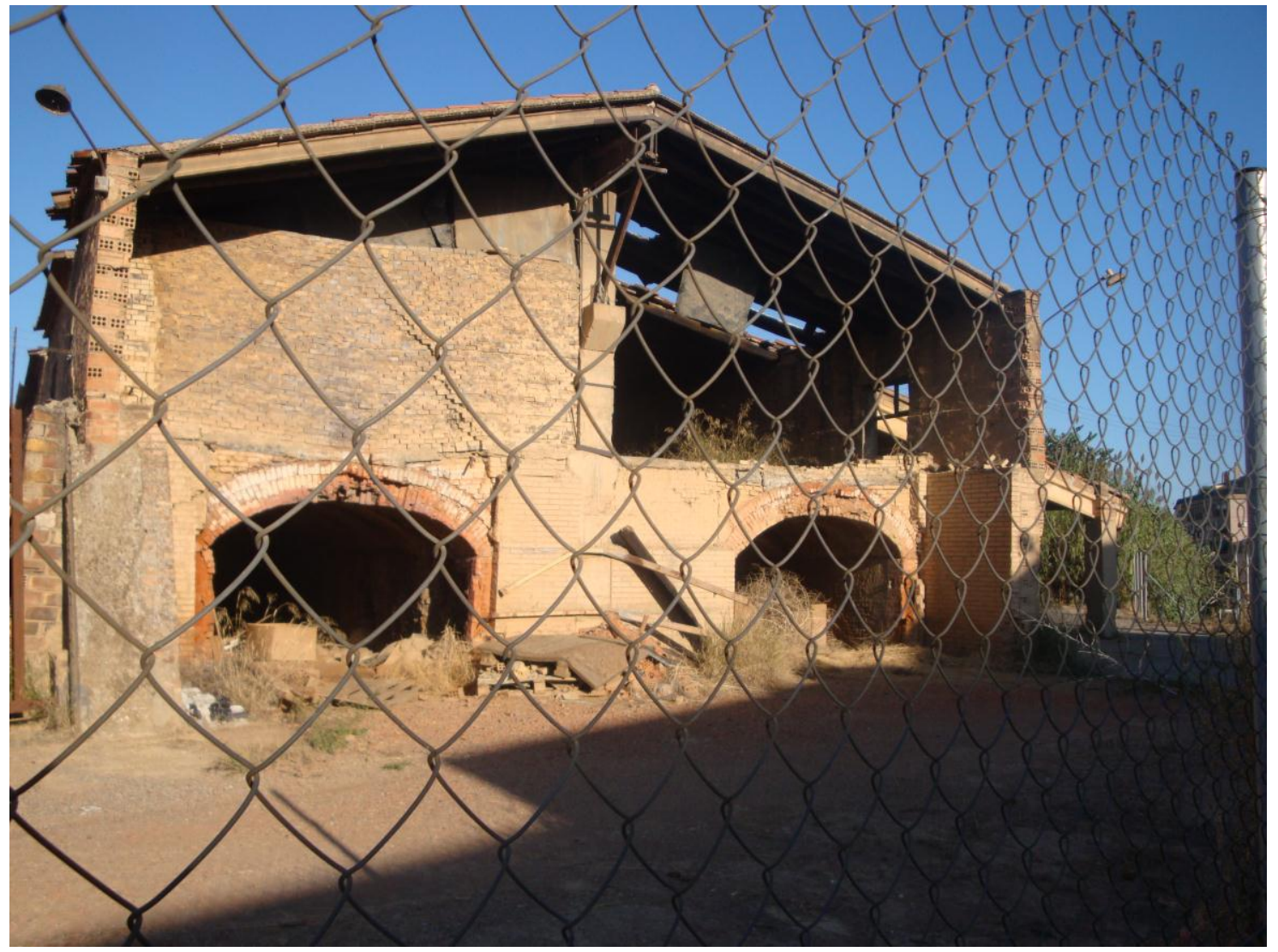

Un aspecto de la fábrica, actualmente cerrada.

PARADA 2. YESERA y YESERÍA, (término municipal de San Esteban de Litera, comarca de la Litera / Llitera). (Hoja 326).

Después de realizar la parada anterior, conviene efectuar un recorrido hasta el cercano pueblo de San Esteban de Litera, a unos $7 \mathrm{Km}$. Allí efectuaremos una nueva parada, concretamente a la salida del pueblo, yendo hacía Peralta de la Sal. 
En este recorrido habremos encontrado afloramientos de los materiales cenozoicos que rellenan la Depresión Geológica del Ebro, en donde nos encontramos ahora situados, desde el inicio del recorrido.

Al respecto, cabe mencionar que hemos ido encontrando abundantes afloramientos de los niveles yesosos y calcolutíticos cenozoicos del Oligoceno Superior, en tránsito al Mioceno. Precisamente, estos son los materiales que predominan en el lugar de la parada. Aquí, éstos han sido explotados en una yesera, para ser utilizados en una yesería.

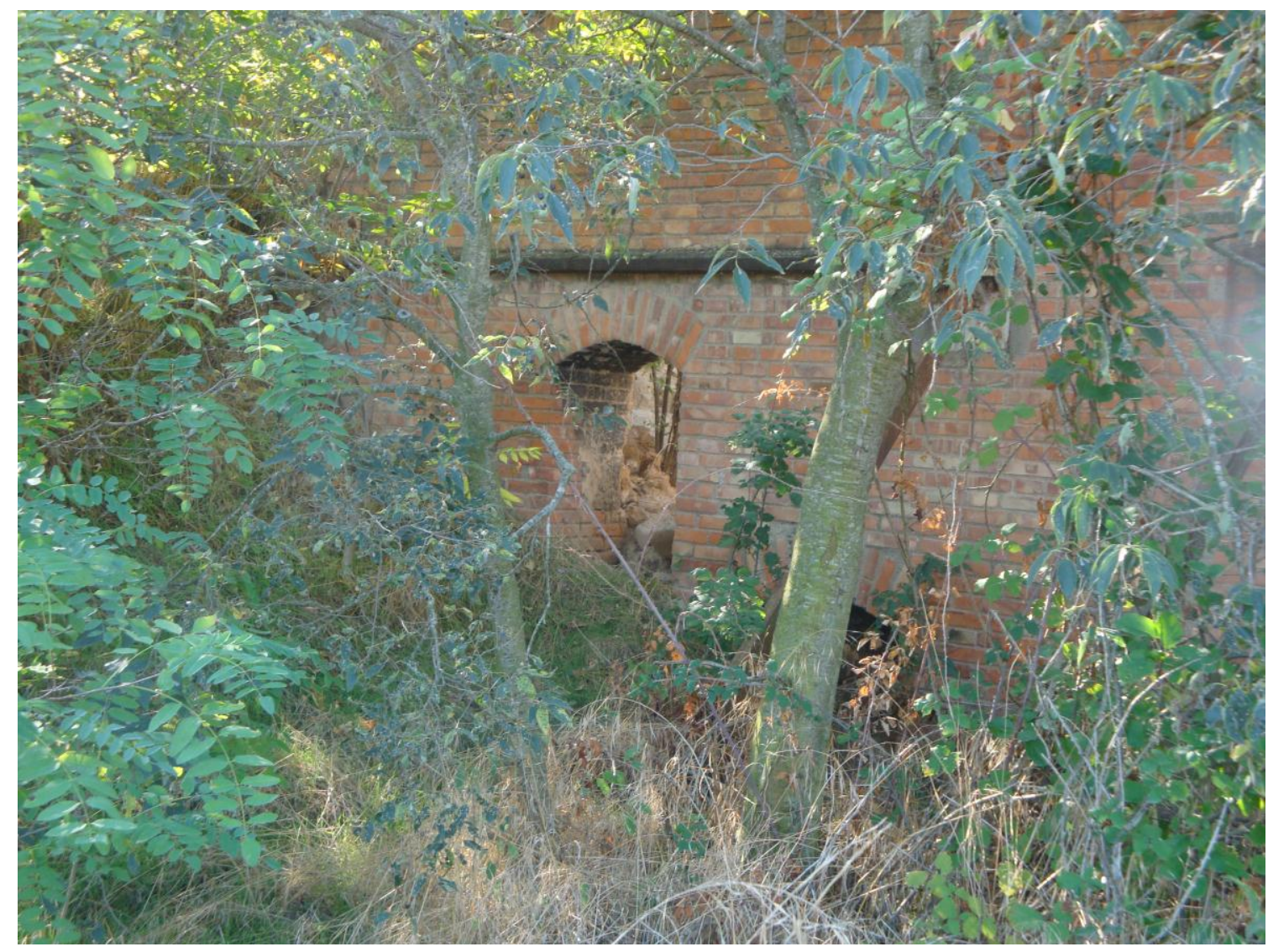

Restos de la yesería (o fábrica de yeso)

En la actualidad, tanto la explotación de yeso (o yesera) como la fábrica (yesería), se hallan completamente abandonadas y en estado de degradación. Sin embargo, cabe considerar que forman parte del patrimonio minero, especialmente la yesería.

PARADA 3. HORNOS DE YESO, (término municipal de San Esteban de Litera, comarca de la Litera / Llitera). (Hoja 326).

Después de realizar la parada anterior, conviene atravesar el pueblo de San Esteban de Litera, con la finalidad de llegar hasta su extremo meridional, en las cercanías de la carretera que conduce desde Binéfar hasta Azanuy. Ahí realizaremos una nueva parada, a menos de $2 \mathrm{Km}$ de la anterior. 
En este recorrido, realizado siempre dentro de la Depresión Geológica del Ebro, hemos ido encontrando abundantes afloramientos de los materiales yesosos y calcolutíticos del cenozoico, predominando los primeros que,han sido explotados en diversos lugares cerca de San Esteban de Litera.

Así, en el lugar de la parada, se observan diversas explotaciones de los yesos cenozoicos. Estos materiales se han utilizado como material de construcción, habiendo sido tratados en diversos hornos de yeso que existen por este sector.

Se trata siempre de pequeñas explotaciones (generalmente artesanales) y de hornos de yeso, que generalmente no se hallan en buen estado de conservación. A pesar de ello forman parte de nuestro patrimonio minero.

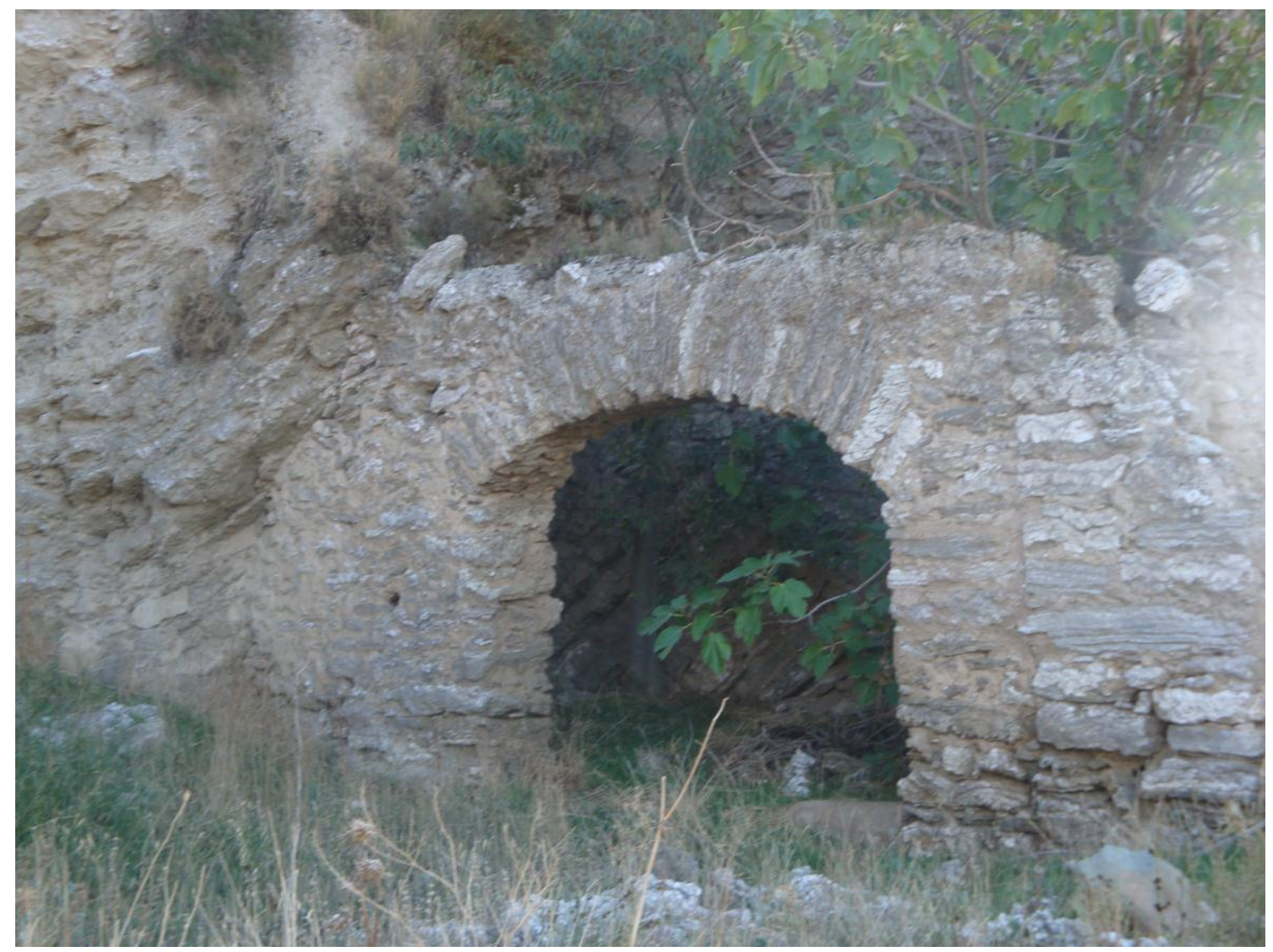

Restos de uno de los hornos de yeso

PARADA 4. GRAVERAS DEL RÍO SOSA, (términos municipales de Azanuy - Alins y de San Esteban de la Litera, comarca de la Litera / Llitera). (Hoja 326).

Después de realizar la parada anterior, conviene continuar por la carretera que conduce hacía la población de Azanuy, yendo siempre hacía el Norte. Sin embargo, a poca distancia de San Esteban de Litera, encontraremos el río Sosa. Al llegar a él lo remontaremos brevemente, con la finalidad de acercarnos a alguna de las explotaciones de áridos que hay en ese lugar. Así, habremos recorrido unos $5 \mathrm{Km}$ más. 
En este recorrido habremos encontrado afloramientos de los materiales cenozoicos mencionados en la parada anterior. Sin embargo, al llegar al río Sosa, habremos encontrado abundantes afloramientos de los materiales cuaternarios que forman parte de las terrazas de este río. Estos materiales tienen clastos carbonatados en su mayoría.

Estos materiales han sido explotados (y aún se siguen explotando) en diferentes graveras situadas a lo largo del cauce, generalmente en las terrazas fluviales del mencionado río Sin embargo, en la mayoría de los casos estas explotaciones se hallan actualmente cerradas.

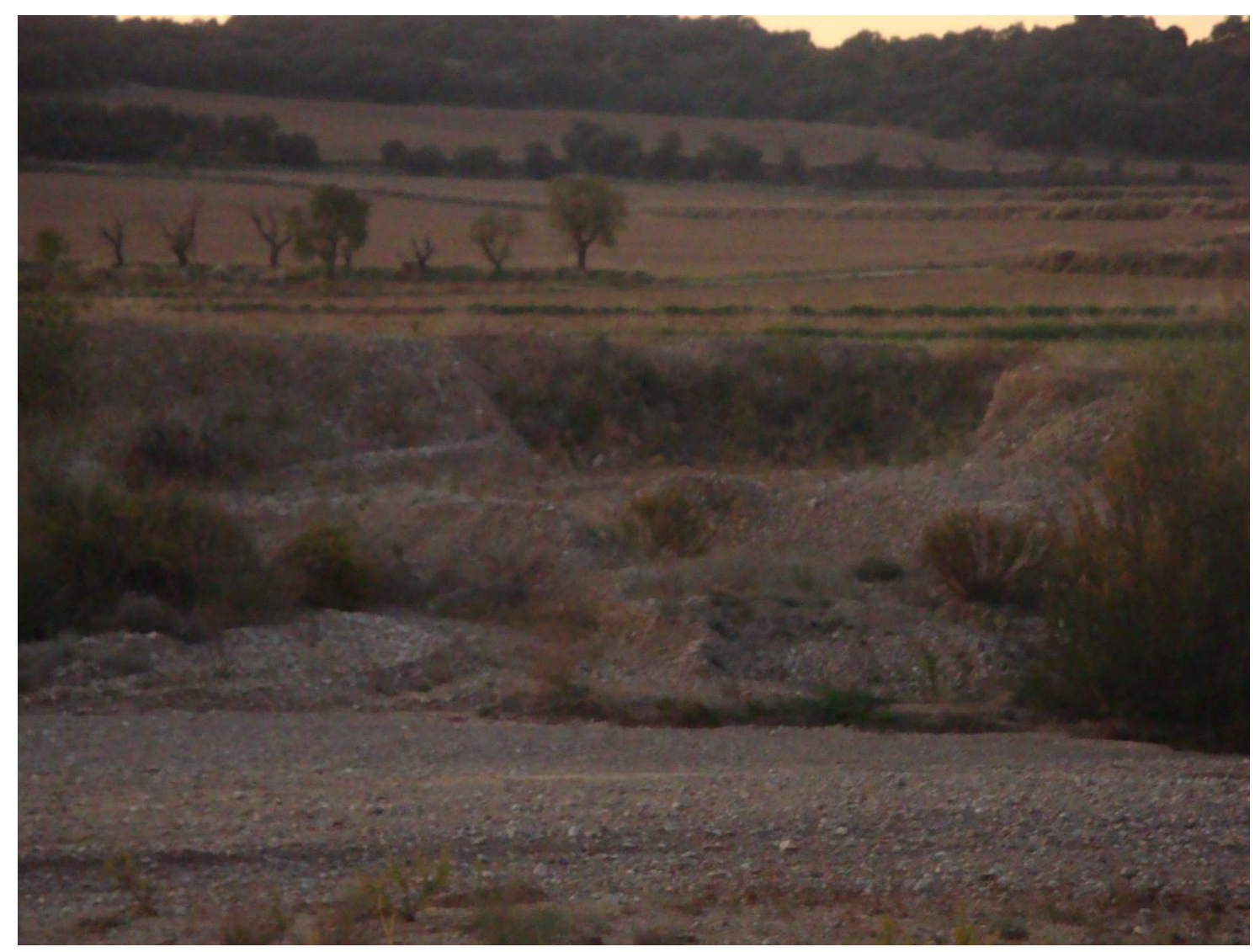

Antigua explotación de gravas

PARADA 5. TAFÓNITOS DEL RÍO SOSA, (término municipal de Azanuy - Alins, comarca de la Litera - Llitera). (Hoja 326).

Tras efectuar la parada anterior, conviene efectuar un breve recorrido, bajando levemente por el mencionado río Sosa. A muy poca distancia del recorrido junto a este río (partiendo de la carretera que desde San Esteban conduce hacía Azanuy), podríamos efectuar una nueva parada, muy cerca de algunas de las explotaciones de áridos. Así, habremos efectuado un recorrido cercano a $0^{\prime} 750 \mathrm{Km}$ desde la parada anterior, como máximo. 
En este recorrido habremos ido encontrando afloramientos de los materiales cenozoicos mencionados en las paradas anteriores. Efectivamente, nos encontramos dentro de la Depresión Geológica del Ebro, en donde hemos iniciado el recorrido y en donde seguimos estando.

En este lugar hay unos afloramientos de niveles detríticos cenozoicos (del tránsito del Oligoceno al Mioceno). Estos son los materiales que aparecen en el lugar de la parada. Sobre ellos se han desarrollado unas interesantes formas erosivas, dando lugar a unos interesantes tafónitos.

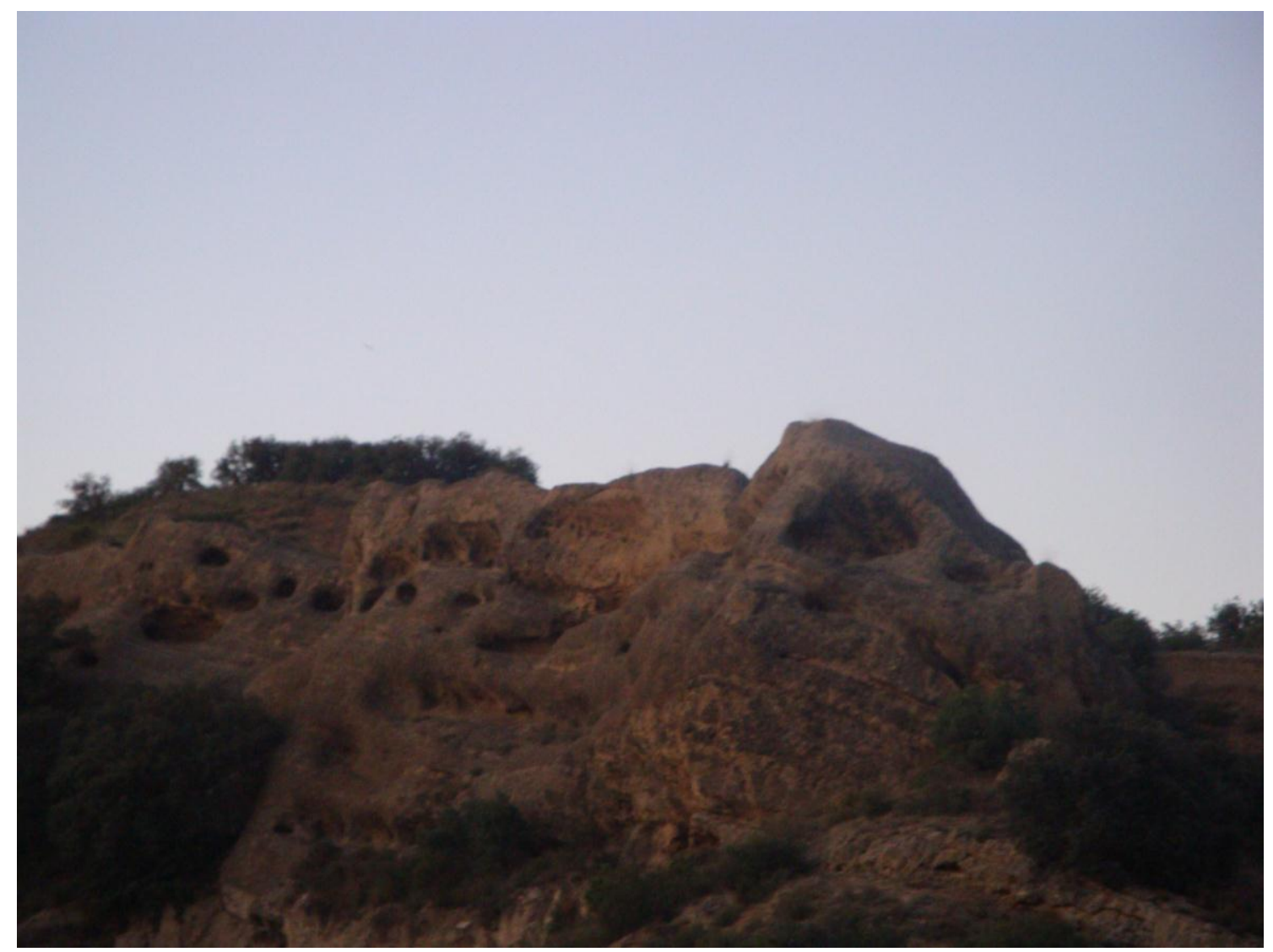

Tafónitos del río sosa (Azanuy - Alins)

PARADA 6. LAS JESERAS, (término municipal de Azanuy - Alins, comarca de la Litera / Llitera). (Hoja 326).

Tras efectuar la parada anterior, conviene dirigirnos hacía la población de Azanuy, yendo siempre hacía el Norte. Tras llegar a la última población citada, nos convendrá continuar hacía Alins. Sin embargo, al llegar al paraje de las Jeseras, efectuaremos una nueva parada, a unos $6-7 \mathrm{Km}$ de la parada anterior.

En este recorrido habremos ido encontrando afloramientos de los materiales cenozoicos mencionados en las paradas anteriores. Así, habremos ido encontrando frecuentes afloramientos de los materiales yesosos cenozoicos, como en las inmediaciones de donde ahora efectuaremos una nueva parada. 
Así, en este lugar han sido explotados estos materiales, para ser utilizados como materia prima para la industria. En este momento, estas explotaciones se hallan cerradas, deteriorándose progresivamente el medio ambiente.

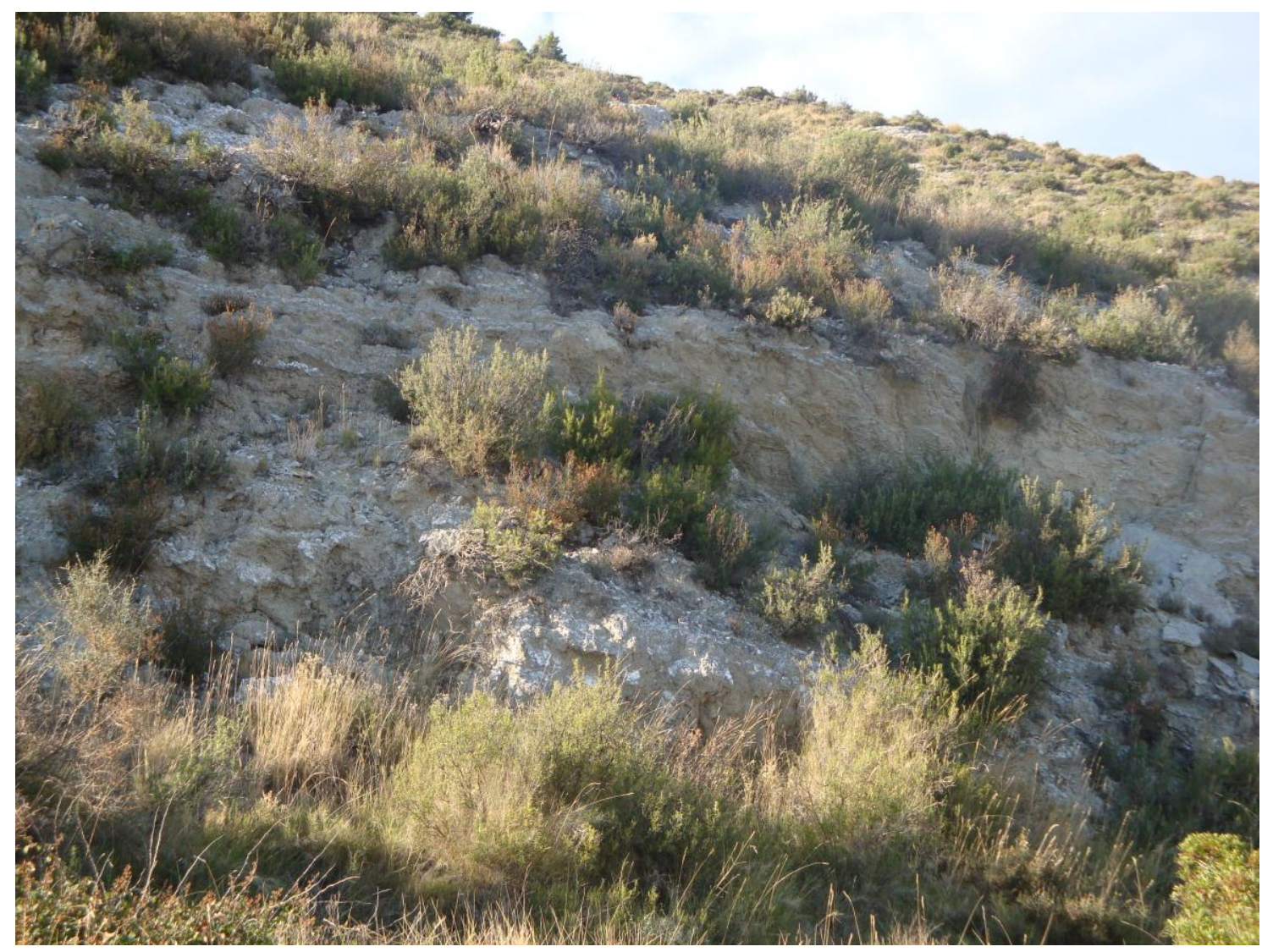

Restos de las antiguas explotaciones de yesos

PARADA 7. LA MINA, (Alins del Monte, término municipal de Azanuy Alins, comarca de la Litera / Llitera). (Hoja 288).

Tras efectuar la parada anterior, conviene continuar por el recorrido que estamos efectuando, con la finalidad de llegar hasta la población de Alins del Monte, en donde efectuaremos la última parte del recorrido de este itinerario. Así, desde la parada anterior habremos recorrido unos $5 \mathrm{Km}$ más.

En este recorrido habremos circulado inicialmente entre afloramientos de los materiales cenozoicos de la Depresión Geológica del Ebro. Luego, ya cerca de Alins del Monte, habremos empezado a encontrar afloramientos mesozoicos del triásico Superior (con tramos de materiales yesosos del Keuper). Luego, habremos encontrado afloramientos carbonatados mesozoicos.

En este lugar hubo una antigua explotación actualmente una minera. Ésta se situaba sobre unos afloramientos carbonatados del Jurásico y del Cretácico. La mineralización era estratiforme., con ESFALERITA y GALENA. A mediados del siglo $\mathrm{XX}$, quedó cerrada la explotación. 


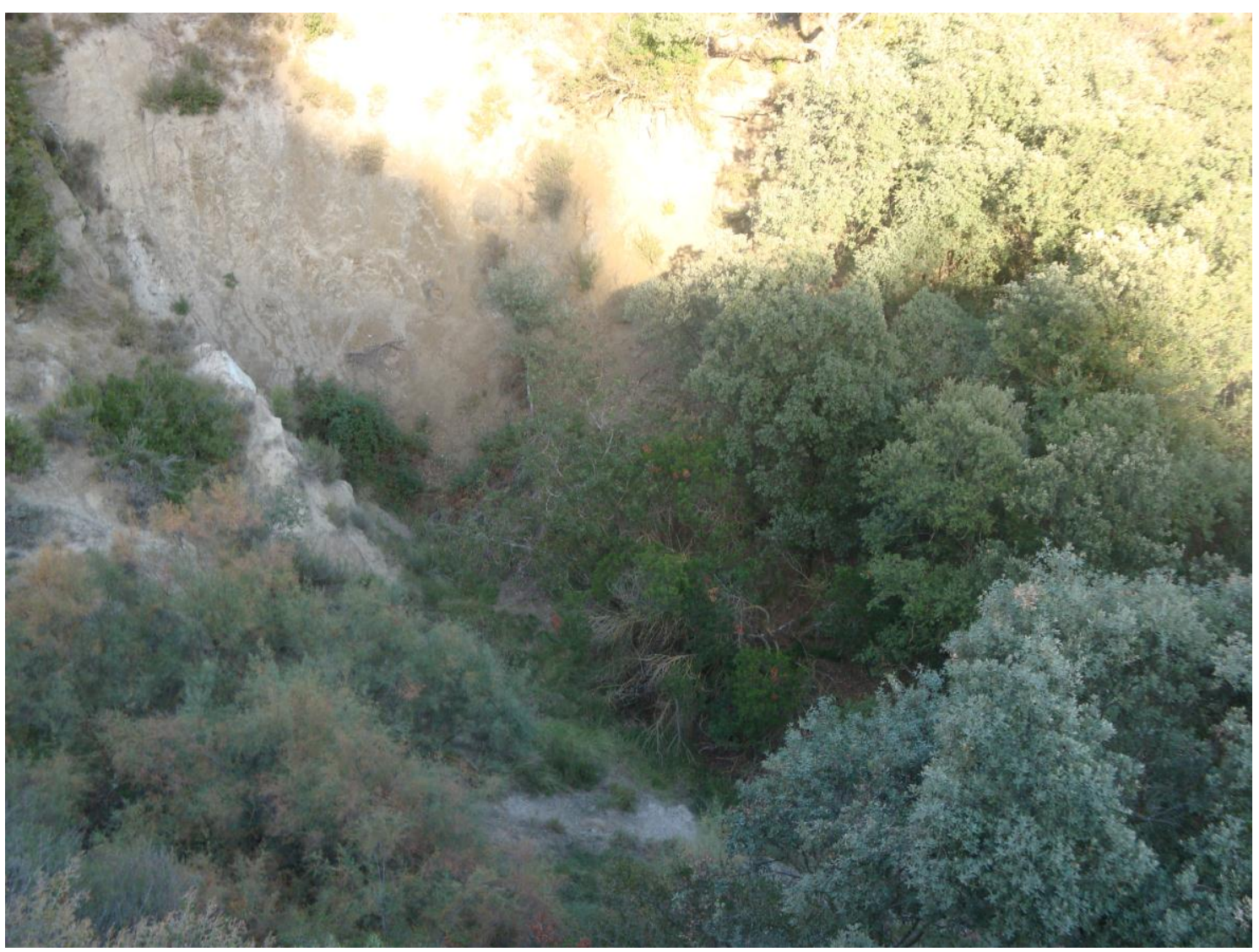

Antigua explotación de "La luna"

Actualmente, en las escombreras aún pueden encontrarse muestras de los minerales acabados de mencionar.

\section{EN ESTE LUGAR FINALIZA EL ITINERARIO}

\section{BIBLIOGRAFÍA}

CALVO, M. et altri (1988).- Minerales de Aragón. Colección Temas geológicos. 200 pag. Zaragoza

GOBIERNO DE ARAGÓN (2001).- Puntos de Interés Geológico de Aragón. Consejería de Medio Ambiente del Gobierno de Aragón. Zaragoza

GUIMERÀ, J. et altri (1992).- Geología (II), Historia Natural de los Países Catalanes, Volum.2, 547 pag. Enciclopèdia Catalana, S.A. Barcelona

IGME (1972).- Mapa Geológico de España a escala 1:200.00 (Síntesis de la Cartografía existente). Hoja y memoria no 23 (Huesca). Inst. Geol. Min. España. Minist. Industria. Madrid

IGME (1974).- Mapa Metalogenético de España a escala 1:200.00. Hoja y memoria $\mathrm{n}^{\text {o }}$ 23 (Huesca). Inst. Geol.Min. España. Minist. Industria. Madrid 
IGME (1975).- Mapa de Rocas Industriales de España a escala 1:200.00. Hoja y memoria $n^{\circ} 23$ (Huesca). Inst. Geol.Min. España. Minist. Industria. Madrid

MAESTRE, A. (1845).- Visita al Distrito Minero de Aragón y Cataluña, Anales de Minas, tomo III, 145 pag. Madrid

MALLADA, L. (1881).- Descripción física y geológica de la provincia de Huesca.Mem. Com. Mapa Geol. De España. Vol. 15. pp. 1 - 439. Madrid

MATA - PERELLÓ, J.; (1987).- Introducción al conocimiento de las mineralizaciones aragonesas. Mineralogistes de Catalunya, t.III, pp. 258-265. Barcelona

MATA - PERELLÓ, J.M. (1990).- Inventario Mineralógico de la Región del Cinca (sectores Orientales). Rodeno, 19. 36 pag. Manresa

MATA-PERELLÓ, J.M. (1991).- Selección de Itinerarios de recerca mineralógica: por la Noguera, la Litera / Llitera i la Baja Ribagorza / Baixa Ribagorça. Xaragall, 27, 36 pag. Manresa

MATA-PERELLÓ, J.M. (1996).- Recerca geològica i mineralògica per les comarques del Segrià, Noguera, Litera / Llitera y Baja Ribagorza / Baixa Ribagorça: des d'Alfarràs a Peralta de la Sal, por Estopiñan / Estopanyà. Inédito, 10 pág. Manresa

MATA-PERELLÓ, J.M. (2002).- Recorregut de recerca geològica i mineralògica per les comarques del Segrià, de la Litera / Llitera i de la Baja Ribagorza / Baixa Ribagorça: des d'Alfarràs a Purroi y en Benabarre, revista Xaragall serie $\mathrm{B}, \mathrm{n}^{\mathbf{o}} 236,12$ pag. Manresa

MATA-PERELLÓ, J.M. i MONTANÉ GARCÍA. P. (2002).- Recorregut de recerca geològica i mineralògica per les comarques del Segrià, la Litera / Llitera i la Baja Ribagorza / Baixa Ribagorça: des d'Alfarràs a Camporrells, a Caladrones / Caladrons i a Benabarre, Inédito, 14 pag. Manresa

MATA-PERELLÓ, J.M. i MONTANÉ GARCÍA. P. (2004).- Recorregut de recerca geològica i mineralògica per les comarques del Segrià, la Litera / Llitera i la Baja Ribagorza / Baixa Ribagorça: des d'Alfarràs a Estopiñan / Estopanyà i a Benabarre, Inédito, 14 pag. Manresa

MATA-PERELLÓ, J.M. i SANZ BALAGUÉ, J. (1989).- Inventari Mineralògic de la comarca de la Litera / Llitera. Revista Tierra Endins, nº 2, 32 pag. Manresa

PRAMES (2005).- Campo de Belchite. Colección RUTASCAL por Aragón. Prames, Gobierno de Aragón. 119 pag. Zaragoza.

RIBA, O. et altri (1976).- Geografía Física de los Países Catalanes, Edit. Ketres, 254 páginas. Barcelona 